\title{
Lubrication by Thin Liquid Films of Aqueous Polymer Solutions
}

\author{
Tadaya KATO, Norio KOZAKI, and Akira TAKAHASHI* \\ Department of Industrial Chemistry, Mie University, \\ Tsu, Mie 514, Japan
}

(Received July 6, 1985)

\begin{abstract}
Lubrication properties of eight water-soluble polymers were studied by measuring the static friction coefficients $\mu_{\mathrm{s}}$ of thin liquid films of these polymer solutions between glass surfaces. Thin liquid films of polymer solutions definitely enhance lubricity even at $C_{\mathrm{p}}=0.01 \mathrm{~g} / 100 \mathrm{ml}$ and reduce the $\mu_{\mathrm{s}}$ values of glass-water-glass interfaces to the extent of 20 to $30 \%$, depending on their chemical structures. Above a concentration of $0.2 \mathrm{~g} / 100 \mathrm{ml}, \mu_{\mathrm{s}}$ becomes constant. Vinylic polymers usually have higher $\mu_{\mathrm{s}}$ than polysaccharides and their derivatives.
\end{abstract}

KEY WORDS Water-Soluble Polymers / Tribology / Adsorption of Polymers / Lubrication / Static Friction Coefficient /

The friction between two solid surfaces originates from molecular attractive force which acts between the two surfaces. The action of a liquid lubricant is that, by being adsorbed on the solid surfaces, lubricant molecules (1) prevent from adhesion of the two solid surfaces and (2) replace the friction between the two surfaces by the friction between the liquid films formed by adsorption of the lubricant molecules on the surfaces. Thus, lubrication is an important surface phenomenon. ${ }^{1}$ For boundary lubrication, Bowden and Tabor ${ }^{2}$ proposed a contact model shown in Figure 1(a). The frictional force $F$ is given by

$$
F=A\left\{\alpha S_{\mathrm{m}}+(1-\alpha) S_{\mathrm{f}}\right\}
$$

where $A$ is the area which supports loading, $\alpha$ is the surface fraction of the solid-to-solid type contact of shear strength $S_{\mathrm{m}}$, and $1-\alpha$ is the fraction of the film-film contact of shear strength $S_{\mathrm{f}}$. Since the load $W$ is expressed as $W=A P_{\mathrm{m}}$, where $P_{\mathrm{m}}$ is a characteristic yield pressure, the friction coefficient $\mu$ is expressed by

\footnotetext{
* To whom correspondence should be addressed.
}

$$
\mu=\frac{F}{W}=\alpha \frac{S_{\mathrm{m}}}{P_{\mathrm{m}}}+(1-\alpha) \frac{S_{\mathrm{f}}}{P_{\mathrm{m}}}
$$

or

$$
\mu=\alpha \mu_{\mathrm{m}}+(1-\alpha) \mu_{\mathrm{e}}
$$

where $\mu_{\mathrm{m}}$ is the friction coefficient between the solid-solid contact part and $\mu_{\mathrm{e}}$ is the friction coefficient of the thin liquid films. Since $\mu_{\mathrm{e}}$ is less than $\mu_{\mathrm{m}}$ it is necessary to decrease $\alpha$ in order to reduce $\mu$, and this is usually achieved by the addition of a low molecular weight additive (lubricant) to liquids. The preferential adsorption of the lubricant in comparison with the liquid becomes pronounced and thus reduces $\alpha$ considerably.

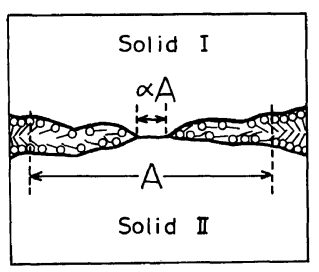

(a)

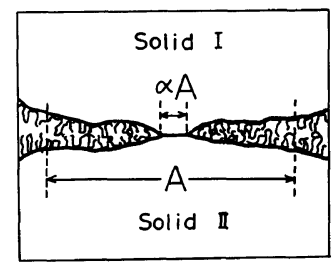

(b)
Figure 1. Model for boundary lubrication. (a) Case of low molecular weight lubricant. (b) Case of adsorbed polymer layer. 
Table I. Constants of the viscosity equation $[\eta]=K M^{v}$ and solvents for each polymers

\begin{tabular}{lccccc}
\hline Sample & $K \times 10^{4}$ & $v$ & Solvent & Temp $/{ }^{\circ} \mathrm{C}$ & References \\
\hline PAAm & 3.09 & 0.67 & Water & 25 & 7 \\
PVA & 4.28 & 0.64 & Water & 30 & 8 \\
PVP & 0.41 & 0.85 & Water & 25 & 9 \\
Pullulan & 1.79 & 0.67 & $0.1 N \mathrm{NaCl}$ aq. & 25 & 6 \\
MC & 3.19 & 0.79 & $0.1 N \mathrm{NaCl}$ aq. & 25 & 10 \\
HEC & 0.953 & 0.87 & Water & 25 & 11 \\
HPC & 8.69 & 0.65 & $0.1 N \mathrm{NaCl}$ aq. & 25 & 10 \\
HPMC & 3.72 & 0.77 & $0.1 N \mathrm{NaCl}$ aq. & 25 & 10 \\
\hline
\end{tabular}

It is now well known that macromolecules can easily be adsorbed onto inorganic surfaces as well as metalic surfaces from dilute solutions. ${ }^{3}$ Therefore, it is expected that adsorbed macromolecules can also act as lubricating additives by reducing $\alpha$ with polymer adsorption as shown in Figure 1(b). Moreover, in a good solvent, interaction between two adsorbed polymer layers is repulsive and this should also reduce $\mu$.

The lubricating action of dilute polymer solutions, especially those of biological macromolecules, is quite important in living processes such as the lubrication of joints. Tachibana ${ }^{4}$ measured the static friction coefficients of gelatin and albumin solutions between glass surfaces, and observed the lubricity of these protein solutions. Recently, certain synthetic water-soluble polymers were found to act as lubricants, especially in the molding processes in fine ceramic industry. However, no report has been published on the friction coefficient of water-soluble polymers in dilute solutions. The purpose of this paper is to measure the static friction coefficients $\mu_{\mathrm{s}}$ for various types of water-soluble polymers and examine the $\mu_{\mathrm{s}}$ values obtained in the light of their chemical structures.

\section{EXPERIMENTAL}

\section{Samples}

Eight water-soluble non-ionic polymers were used in this work. Poly(acrylamide) sample (PAAm) was prepared by radical poly-
Table II. Molecular characteristics of samples

\begin{tabular}{lcccc}
\hline Sample & {$[\eta] / \mathrm{dlg}^{-1}$} & $M_{v} / 10^{4}$ & $\mathrm{DS}^{\mathrm{a}}$ & $\mathrm{MS}^{\mathrm{b}}$ \\
\hline PAAm & 2.95 & 87.1 & & \\
PVA & 0.40 & 4.4 & & \\
PVP & 1.60 & 25.2 & & \\
Pullulan & 0.85 & 30.7 & & \\
MC & 1.83 & 5.73 & 1.76 & - \\
HEC & 2.16 & 10.1 & - & 1.8 \\
HPC & 1.26 & 7.3 & - & 3.0 \\
HPMC & 13.8 & 85.9 & 1.89 & 0.27 \\
\hline
\end{tabular}

a Degree of substitution (DS) is the number of sites at which modification is made in an anhydroglucose unit.

b Degree of molar substitution (MS) is the total number of propylene oxide or ethylene oxide molecules which reacted with one glucose unit.

merization with ammonium persulfate and $N, N, N^{\prime}, N^{\prime}$-tetramethylethylenediamine as the initiators in MacIlvaine buffer solution $(\mathrm{pH}=4.7)$ to prevent hydrolysis of the amide unit in the monomer. The sample was dissolved in distilled water and was fractionated by the addition of methanol as precipitant at $25^{\circ} \mathrm{C}$. The adequate fraction was used as the sample in this work. Poly(vinyl alcohol) sample (PVA, 88\% hydrolyzed) was purchased from Katayama Kagaku Co., Japan, and the nominal molecular weight was reported as $M=4 \times 10^{4}$. Poly(vinylpyrrolidone) sample (PVP, designated as K90) was purchased from Tokyo Kasei Co., Japan, and precipitated from aqueous solution by the addition of acetone. Methyl cellulose (MC, Metolose SM25) and hydroxypropyl-methyl cellulose (HPMC, Metolose 60SH4000) were supplied 


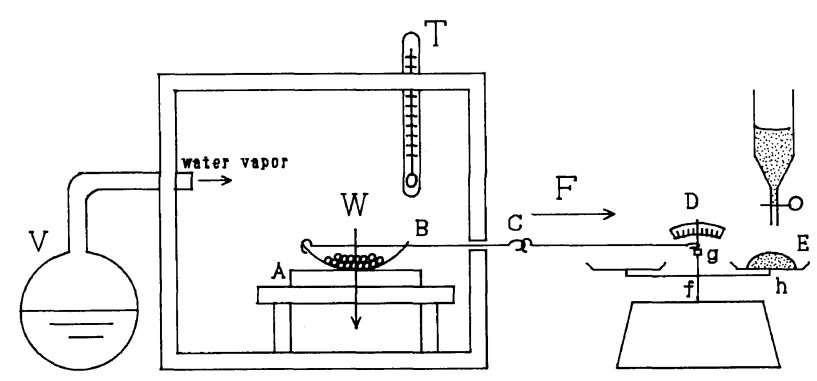

Figure 2. Schematic representation of the apparatus for static friction coefficient measurement. $T$ is a thermoregulator. For the other symbols, see the text.

by Shin-Etsu Chemical Co., Japan. Hydroxyethyl cellulose (HEC, CELLOSIZE WP3L) was purchased from Union Carbide Corp., U.S.A. Hydroxypropyl cellulose (HPC, designated as HPC-L) was purchased from Nippon Soda Co., Japan. These four cellulose derivatives were purified by dissolving them in cold water, precipitating in acetone or methanol and washing the precipitates by dried methanol. Pullulan (PF30) was supplied by Hayashibara Biochemical Laboratories, Inc., Japan. The purification and fractionation were reported in previous papers. ${ }^{5,6}$ Each polymer sample was dried overnight in vacuo at room temperature. Intrinsic viscosities $[\eta]$ were measured on an Ubbelohde-type viscometer. The kinetic energy correction was always negligible.

The molecular weight of each polymer was determined by intrinsic viscosity measurement. The solvents and viscosity-molecular weight equations used were listed in Table I. The degree of substitution of methoxy groups of MC and HPMC and the number of propylene oxide and ethylene oxide molecules reacted with one glucose unit (degree of molar substitution) of HPMC, HPC and HEC were determined by the Zeisel-gas chromatography method. ${ }^{12,13}$ The results of molecular characterization of samples are shown in Table II.

Twice distilled water was used as solvent. Watch glasses and optical flat plate glasses, supplied from Central Glass Co., Japan were first dipped into a warm $\mathrm{H}_{2} \mathrm{SO}_{4}-\mathrm{HNO}_{3}$ (1:1 vol. ratio) mixture, then thoroughly washed in distilled water and dried in a dust free box.

\section{Static Friction Coefficient}

Static friction coefficients for thin liquid films of aqueous polymer solutions between glass surfaces were measured by Sameshima's apparatus $^{14}$ shown in Figure 2. A is a glass plate $(10 \mathrm{~cm} \times 10 \mathrm{~cm} \times 0.5 \mathrm{~cm})$ and $B$ is a watch glass $(\phi=9 \mathrm{~cm})$, which acts as a slider and its weight $W$ is adjusted by putting lead shots in it. $C$ is a thin steel wire one end of which is hitched to the cutting of the watch glass $B$. The other end of $C$ is connected to the pointer $D$ of a prescription balance. Both $\mathrm{A}$ and $\mathrm{B}$ are located in a thermostated transparent plastic box. Water vapor was supplied from a vaporizer $V$ to keep the saturated vapor pressure at a specified temperature in the box, and the vapor pressure was checked by a hygrometer placed in the box.

An aqueous polymer solution $(0.15 \mathrm{ml})$ of a specified concentration was placed between B and A. Fine sand was poured as a small stream from a reservoir $R$ onto the right pan $E$.

Addition of sand is continued until the pan at the right moves downward, the pointer inclines to the right side and the slider $B$ moves to the right. The weight of sand is measured. When the weight of sand is $s$, the length between $f$ and $g$ is $l$, and the distance between $f$ and $h$ is $l^{\prime}$, then the force $F$ acting on the slider $B$ is given by 


$$
F=s \frac{l^{\prime}}{l}
$$

The static friction coefficient $\mu_{\mathrm{s}}$ is given by

$$
\mu_{\mathrm{s}}=\frac{F}{W}
$$

For a specified polymer concentration and $W$, at least eleven measurements of $F$ were performed and then the averaged $F$ value was used in eq 5 .

\section{RESULTS AND DISCUSSION}

As examples, Figure 3 shows the static friction coefficient $\mu_{\mathrm{s}}$ of five aqueous polymer solutions of (concentration: $0.1 \mathrm{~g} / 100 \mathrm{ml}$ ) as a function of weight $W$. At less than $W=120 \mathrm{~g}$, $\mu_{\mathrm{s}}$ increases with a decrease in $W$; however, when $W$ is more than $120 \mathrm{~g}, \mu_{\mathrm{s}}$ becomes constant. According to the famous Coulomb's experiment, ${ }^{15} F$ is expressed as

$$
F=A+\mu_{1} W
$$

where $A$ is a constant and $\mu_{1}$ is a friction coefficient. Then $\mu_{\mathrm{s}}$ is given by

$$
\mu_{\mathrm{s}}=\frac{F}{W}=\mu_{1}+\frac{A}{W}
$$

Equation 7 indicates that when vertical force, $W$ in this case, is very small, $\mu_{\mathrm{s}}$ becomes very large and with increasing $W$, it approaches asymptotically to a constant value $\mu_{1}$. In Figure 4, $F$ is plotted against $W$ according to eq 6 and from the slope, we can determine $\mu_{1}$ with the least square method. Even at present, the physical meaning of the constant $A$ is obscure, but it is independent of $W$ and is called the adhesion force. Moreover, when $W$ is larger than around $120 \mathrm{~g}$, the values of the second term $(A / W)$ on the righthand side of eq 7 become smaller. $\mu_{1}$ is thus practically equal to $\mu_{\mathrm{s}}$.

In the following, we employed the $\mu_{1}$ values as $\mu_{\mathrm{s}}$ for different polymer concentrations. The experimental errors in $\mu_{\mathrm{s}}$ values at a relevant

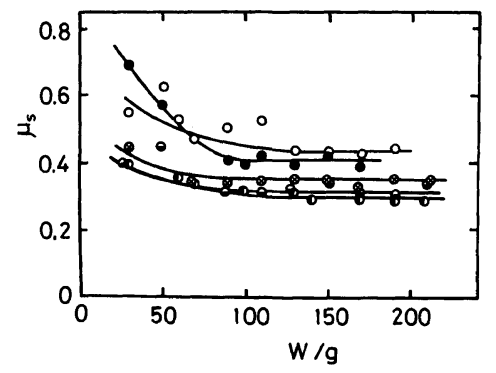

Figure 3. Static friction coefficient $\mu_{\mathrm{s}} v s$. weight $W$ plots for the five polymer solutions. Polymer concentration: $0.1 \mathrm{~g} / 100 \mathrm{ml}$. О, PAAm: $\otimes$, PVP; $\bigcirc$ MC; $\boldsymbol{D}$, HEC; $\ominus$, HPMC.

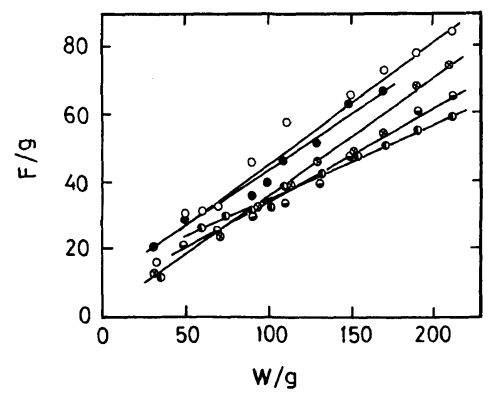

Figure 4. Force $F$ vs. $W$ plots for the five polymer solutions. Symbols are the same as in Figure 3.

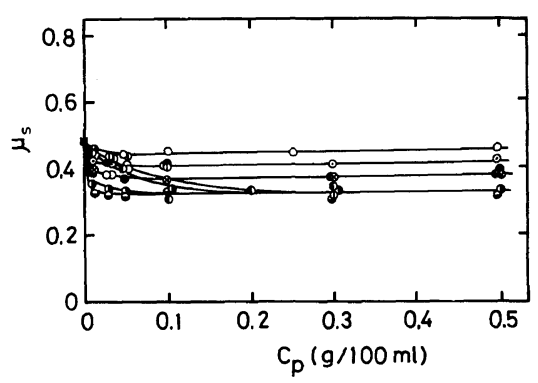

Figure 5. Polymer concentration dependence of $\mu_{\mathrm{s}}$ of the eight polymer samples. $\square$, solvent $\left(\mathrm{H}_{2} \mathrm{O}\right) ; \mathrm{O}$, PAAm; $\otimes$, PVP; $\odot$, PVA; (1), Pullulan; O, MC; 1 , HEC; $\odot$, HPC; $\odot$, HPMC.

polymer concentration were less than $5 \%$. Next, $\mu_{\mathrm{s}}$ values of the eight polymer samples were plotted against the polymer concentrations in Figure 5. Except for pullulan and HEC, $\mu_{\mathrm{s}}$ steeply decreases by the addition of polymers, notably even at $0.01 \%$ polymer solutions. It decreases from $\mu_{\mathrm{s}}=0.500 \pm 0.010$ of 
Lubrication by Water-Soluble Polymers

Table III. Static friction coefficients $\mu_{\mathrm{s}}$ of thin liquid films of polymer solutions

\begin{tabular}{|c|c|c|c|}
\hline Polymer & $\mu_{\mathrm{s}}$ & Backbone & Functional groups \\
\hline PAAm & $0.445 \pm 0.010$ & $\left(\mathrm{CH}_{2}-\mathrm{C} \mathrm{H}\right)_{n}$ & $\mathrm{R}=-\mathrm{CONH}_{2}$ \\
\hline PVA & $0.390 \pm 0.007$ & $\left(\mathrm{CH}_{2}-\mathrm{CH}\right)_{n}$ & $\mathrm{R}=-\mathrm{OH}$ \\
\hline PVP & $0.350 \pm 0.012$ & $\left(-\mathrm{CH}_{2}-\mathrm{C} \mathrm{H}\right)_{n}$ & $\mathrm{R}=-\mathrm{N}^{\prime} \mathrm{CH}_{2}-\mathrm{CH}_{2}$ \\
\hline $\mathrm{MC}$ & $0.387 \pm 0.012$ & $\operatorname{Poly}(\beta$-1,4-glucose $)$ & $\mathrm{R}=-\mathrm{OH},-\mathrm{OCH}_{3}$ \\
\hline HEC & $0.307 \pm 0.005$ & $\operatorname{Poly}(\beta$-1,4-glucose $)$ & $\mathrm{R}=-\mathrm{OH},-\mathrm{OC}_{2} \mathrm{H}_{4} \mathrm{OH}$ \\
\hline Pullulan & $0.329 \pm 0.011$ & $\operatorname{Poly}(\beta-1,4$ and $\beta$-1,6-glucose $)$ & $\mathrm{R}=-\mathrm{OH}$ \\
\hline HPC & $0.322 \pm 0.008$ & $\operatorname{Poly}(\beta$-1,4-glucose $)$ & $\mathrm{R}=-\mathrm{OH},-\mathrm{OC}_{3} \mathrm{H}_{6} \mathrm{OH}$ \\
\hline HPMC & $0.312 \pm 0.008$ & Poly $(\beta$-1,4-glucose $)$ & $\mathrm{R}=-\mathrm{OH},-\mathrm{OCH}_{3},-\mathrm{OC}_{3} \mathrm{H}_{6} \mathrm{OH}$ \\
\hline
\end{tabular}

the water film to $\mu_{\mathrm{s}}=0.31 \sim 0.45$ and then becomes constant irrespective of polymer concentration. It is clear that all water-soluble synthetic polymers as well as pullulan have lubricating action.

Table III shows a comparison of the $\mu_{\mathrm{s}}$ values of various polymer obtained by averaging the values for polymer concentrations of more than $0.2 \mathrm{~g} / 100 \mathrm{ml}$. In general, depending on their chemical structures, it appears that vinylic polymers have slightly higher $\mu_{\mathrm{s}}$ values than polysaccharides and their derivatives except methylcellulose. Probably, the polysaccharide chains have a flat conformation on the glass surface and this may be favorable for reducing $\mu_{\mathrm{s}}$ values.

In most experiments of polymer adsorption onto solid surfaces, the adsorption isotherm steeply increases first with increasing bulk polymer concentration and reaches a plateau region, while the shape of the $\mu_{\mathrm{s}} v s$. polymer concentration curve is just a mirror image of the shape of the adsorption isotherm. Therefore, to obtain more information about the molecular mechanism of lubricating action of these polymers, it is necessary not only to determine the adsorption isotherms onto glass surfaces but measure the thickness of the adsorbed layer; these studies are now in progress.

In conclusion, thin liquid films of watersoluble polymers definitely have lubricity and reduce the $\mu_{\mathrm{s}}$ values of glass-water-glass interface as much as 20 to $30 \%$, depending on their chemical structures.

Acknowledgments. The fellowship given by Shinetsu Chemical Co., Ltd. is greatly appreciated. We also thank Messrs Y. Onda, S. Nakamura, and K. Hayakawa for their comments.

\section{REFERENCES}

1. A. W. Adamson, "Physical Chemistry of Surface," 4th Ed., John Wiley and Sons, New York, N. Y., 1982.

2. F. P. Bowden and D. Tabor, "The Friction and Lubrication of Solid," Part II. The Clarendon Press, Oxford, 1964; "The Friction and Lubrication of Solid," Oxford University Press, 1950.

3. A. Takahashi and M. Kawaguchi, Adv. Polym. Sci., 46, 1 (1982).

4. T. Tachibana, Nippon Kagaku Kaishi, 69, 103 (1948).

5. T. Kato, T. Okamoto, T. Tokuya, and A. Takahashi, Biopolymers, 21, 1623 (1982).

6. T. Kato, T. Tokuya, and A. Takahashi, $J$. Chromatogr., 256, 61 (1983).

7. P. Munk, T. M. Aminabhavi, P. Williams, D. E. Hoffman, and M. Chmelir, Macromolecules, 13, 871 (1980).

8. M. Matsumoto and Y. Ohyanagi, Kobunshi Kagaku, 17, 191 (1960).

9. L. E. Miller and F. A. Hamm, J. Phys. Chem., 57, 110 (1953).

10. T. Kato, T. Tokuya, and A. Takahashi, unpublished data. Weight average molecular weights of these sample fractions were measured by an aqueous GPC/LS method. 
11. W. Brown, D. Henley, and J. Oehman, Makromol. Chem., 64, 49 (1963).

12. R. U. Lemieux and C. B. Purves, Can. J. Res., B-25, 485 (1947).

13. J. G. Cobler, E. P. Samsel and G. H. Beaver, Talanta, 9, 479 (1962).
14. J. Sameshima, M. Kidokoro and H. Akamatsu, Bull. Chem. Soc. Jpn., 11, 659 (1936).

15. C. A. Coulomb, "Mémories de Mathématiquie et de Physique," l'Académie Royale des Sciences, 1785, p 161. 